The rest that may be secured to the inflamed surfaces and tissues by the combined effect of opium and strapping is more perfect, I think, than can be secured otherwise. Besides, by thus early and decidedly controlling the motion of respiration upon the affected side, I think that effusion is much less likely to occur, for if we save the friction of the roughened pleural surfaces, our case is likely to be relieved by an arrest of the inflammatory process before it arrive at the stage of effusion. In cases unmodified by art the effusion is the means for relieving the friction and the pain, and is brought about only by the full development of the inflammatory process.

\title{
A FIBRO-CYSTIC TUMOR OF THE UTERUS CURED BY ERGOT.
}

BY H. A. DEAN, M. D., ATHOL, MASS.

THE following case is reported, not for any originality of treatment, but to substantiate the results obtained by others in the use of ergot, and to encourage its further trial by the profession in similar cases.

Mrs. G. K., age forty-two, first had uterine trouble in June, 1868. A long ride and tramp for berries were followed by a severe uterine hæmorrhage, and menorrhagia was the rule at each catamenial period for several months following. She first noticed a tumor of the size of a teacup in May, 1869, but received no treatment till the next September. She has been for most of the time since under treatment, principally by irregular practitioners. All this time the tumor had gradually increased in size, until it gave her the appearance of a woman at the full term of pregnancy.

I was first called to the case January 23, 1877 ; found her suffering from poor circulation, difficult breathing, numbness of extremities, feeble pulse, and general œedema, and ordered hydrarg. chlorid. mit., fifteen grains, to be followed by a saline cathartic in the morning. This treatment gave general relief. The patient at first objected to any direct treatment for the tumor, saying it always made her worse, but she finally consented, about the middle of March, to take the ergot in onehalf-drachm doses three times daily.

The 27th of March, my friend Dr. H. T. Hawks, of New York city, saw the case. He made a thorough examination, exploring by aspirating needle and by uterine sound. He diagnosticated a very large fibro-cystic tumor. The cavity of the uterus measured seven inclies in length, bearing far to the left. The aspirator produced but little fluid. His prognosis was unfavorable, but he advised an increased dose of the ergot, giving drachm doses once in four hours.

The $3 \mathrm{~d}$ of April she commenced flowing profusely, was in great pain, 
delirious, with quick pulse and high fever. I found general inflammation of uterus and bowels. The ergot nauseated her, so it was ordered by enema. Squibb's tr. opii deod. and hot fomentations over the bowels were prescribed. The menorrhagia, delirium, and fever lasted for two weeks, with no abatement. The patient became emaciated and extremely weak, and the end seemed but a few days off. The third week of fever found her mind becoming clearer, fever abating from $103^{\circ}$ to $100^{\circ}$, pulse falling from 130 to 110 , and the uterine discliarge free from blood, but more excessive than before, and occasionally small pieces of fibrous tissue came away with it. These increased in size and frequency, some days several pieces the size of a hen's egg passing off, until the whole mass had disappeared. A thin offensive discharge kept up for a few weeks, but soon ceased altogether, and in October the menses, absent since April, returned. The patient is in full flesh, natural figure, and, as she expresses it, " never felt better in her life." The only treatment not mentioned above was the administration of infusion of digitalis, with general supporting tonic remedies, iron, quinine, porter, etc.

\section{RECENT PROGRESS IN THE TREATMENT OF CHILDREN'S DISEASES. ${ }^{1}$}

BY D. H. HAYDEN, M. D.

Diphtheria and Croup. ${ }^{2}-$ From the author's historico-geographic account of diphtheria the following is a resume of conclusions arrived at: Diphtheria belongs to the oldest of diseases to which a people are subject. Accounts of epidemics of this disease date back to the sixteenth century. Its disappearance from time to time, and occasionally, too, for a longer series of years than has been observed with other diseases, is one of its peculiarities. After such a disappearance at the beginning of this century it has again, since 1820, extended from France into other countries. It invades all portions of the globe, irrespective of the climate, elevation above the sea, or the character of the soil. There are numerous facts that speak for its indigenous character. It has often extended itself on the sea; and in inland countries its progress is not limited to the lines of travel. Sporadic cases, generally of severe character, always precede an epidemic of the disease. Whenever it once enters a large city it installs itself there permanently. In the sixteenth century it reigned epidemically for from thirty to forty years.

The second part of the article is devoted to the ætiology of the dis-

1 Concluded from page 79.

2 F. Seitz, Berlin, 1877, Grieben, 8vo, 516 pages. Centralblatt für die medicinischen Wissenschaften, November 17, 1877, No. 46. 